\title{
Dopamine adjusts the circadian gene expression of Per2 and Per3 in human dermal fibroblasts from ADHD patients
}

\author{
Frank Faltraco ${ }^{1}$. Denise Palm ${ }^{1} \cdot$ Adriana Uzoni $^{1} \cdot$ Lena Borchert $^{1}$. Frederick Simon ${ }^{1}$. Oliver Tucha ${ }^{1}$. \\ Johannes Thome ${ }^{1}$
}

Received: 12 January 2021 / Accepted: 27 June 2021 / Published online: 18 July 2021

(c) The Author(s) 2021

\begin{abstract}
A link between dopamine levels, circadian gene expression, and attention deficit hyperactivity disorder (ADHD) has already been demonstrated. The aim of this study was to investigate the extent of these relationships by measuring circadian gene expression in primary human-derived dermal fibroblast cultures (HDF) after dopamine exposure. We analyzed circadian preference, behavioral circadian and sleep parameters as well as the circadian gene expression in a cohort of healthy controls and participants with ADHD. Circadian preference was evaluated with German Morningness-Eveningness-Questionnaire (D-MEQ) and rhythms of sleep/wake behavior were assessed via actigraphy. After ex vivo exposure to different dopamine concentrations in human dermal fibroblast (HDF) cultures, the rhythmicity of circadian gene expression (Clock, Bmall, Per1-3, Cryl) was analyzed via qRT-PCR. We found no statistical significant effect in the actigraphy of both groups (healthy controls, ADHD group) for mid-sleep on weekend days, mid-sleep on weekdays, social jetlag, wake after sleep onset, and total number of wake bouts. D-MEQ scores indicated that healthy controls had no evening preference, whereas subjects with ADHD displayed both definitive and moderate evening preferences. Dopamine has no effect on Per3 expression in healthy controls, but produces a significant difference in the ADHD group at ZT24 and ZT28. In the ADHD group, incubation with dopamine, either $1 \mu \mathrm{M}$ or $10 \mu \mathrm{M}$, resulted in an adjustment of Per3 expression to control levels. A similar effect also was found in the expression of Per2. Statistical significant differences in the expression of Per2 (ZT4) in the control group compared to the ADHD group were found, following incubation with dopamine. The present study illustrates that dopamine impacts on circadian function. The results lead to the suggestion that dopamine may improve the sleep quality as well as ADHD symptoms by adjustment of the circadian gene expression, especially for Per 2 and Per3.
\end{abstract}

Keywords ADHD Dopamine $\cdot$ Human dermal fibroblasts $\cdot$ Circadian rhythm

\section{Introduction}

Dopamine is produced by dopaminergic neurons in the brain from aminoacid tyrosine, which is converted into dihydroxyphenylalanine (DOPA) by a rate-limiting enzyme, tyrosine hydroxylase (TH) (Tekin et al. 2014). Dopamine $\beta$ hydroxylase (DBH) is an enzyme responsible for the conversion of dopamine into catecholamine neurotransmitter noradrenaline (Catelas et al. 2020). Circadian variations in the activity of tyrosine hydroxylase and dopamine $\beta$ hydroxylase were

Frank Faltraco

frank.faltraco@med.uni-rostock.de

1 Department of Psychiatry and Psychotherapy, University Medical Centre Rostock, Gehlsheimer Str. 20,

18147 Rostock, Germany observed in the rat brain stem and Perlb mutant zebrafish (Cahill and Ehret 1981; Huang 2015).

After biosynthesis, dopamine is packaged and stored into a synaptic vesicle by the vesicular monoamine transporter 2 (VMAT2) (Roeder 2002). A plasma membrane protein dopamine transporter (DAT), encoded by SLC6A3 gene, controls both extracellular and intracellular concentrations of dopamine (McHugh and Buckley 2015; Salatino-Oliveira et al. 2018). Dopamine neurotransmitters bind to five subtypes of dopamine receptors: $\mathrm{D}_{1}, \mathrm{D}_{2}, \mathrm{D}_{3}, \mathrm{D}_{4}$, and $\mathrm{D}_{5}$, divided into two major subclasses: D-1-like and D-2-like members of the G-protein coupled receptor family (Beaulieu et al. 2015; Xin et al. 2019). When administered in critical care and emergency settings, dopamine acts as a non-selective drug and an agonist of $\alpha$-, and $\beta$-adrenergic receptors (Farzam et al. 2020). Infused at low doses, between 0.5 and 
$3.0 \mu \mathrm{g} / \mathrm{kg} / \mathrm{min}$, dopamine increases diuresis, splanchnic blood flow and natriuresis. At higher doses than $3 \mu \mathrm{g} / \mathrm{kg} /$ min dopamine stimulates $\beta$-adrenergic receptors increasing cardiac inotropy and chronotropy, whereas doses higher than $7 \mu \mathrm{g} / \mathrm{kg} / \mathrm{min}$ result in $\alpha$-adrenergic stimulation with peripheral and splanchnic vasoconstriction (MacGregor et al. 2000). In critically ill new-born infants, plasma dopamine concentrations range from $0.5 \mathrm{ng} / \mathrm{ml}$ to almost $70 \mathrm{ng} / \mathrm{ml}$, at an infusion rate of 4-8 $\mu \mathrm{g} / \mathrm{kg} / \mathrm{min}$ (Padbury et al. 1990). In hemodynamically stable children, the half-lives of distribution and elimination were $1.8 \mathrm{~min}$ and $26 \mathrm{~min}$, respectively. The apparent volume of distribution was $2952 \pm 2332 \mathrm{~mL} /$ $\mathrm{kg}$, and clearance rate was $454 \pm 900 \mathrm{~mL} / \mathrm{kg} / \mathrm{min}$ (Eldadah et al. 1991). In healthy male volunteers, injected with $3 \mu \mathrm{g} /$ $\mathrm{kg} / \mathrm{min}$ infusions for $90 \mathrm{~min}$, steady-state dopamine concentrations varied from 1880 to $18,300 \mathrm{ng} / \mathrm{l}$. After $10 \mathrm{~min}$ of dopamine infusion at $10 \mu \mathrm{g} / \mathrm{kg} / \mathrm{min}$ plasma concentrations of dopamine varied from 12,300 to $201,500 \mathrm{ng} / \mathrm{l}$, suggesting intra-individual and inter-individual variability in dopamine distribution and metabolism (MacGregor et al. 2000).

Dopamine is degraded by monoamine oxidase (MAO) in the cytosol and catechol-O methyl transferase (COMT) in the surrounding glial cells (Meiser et al. 2013). Main degradation products of dopamine are reactive 3, 4-dihydroxyphenylacetaldehyd and homovanilic acid (HVA) (Eisenhofer et al. 2004). Dopamine and its metabolites are metabolized by phase II conjugation reactions (Uutela et al. 2009).

Dopamine plays important roles in executive function, motor control, motivation, arousal, reinforcement, and reward through signaling cascades (Awata et al. 2015; Blenau and Baumann 2001; Waddell 2013). Studies have suggested that dopamine mediates learned associations between stimuli and reward (Beeler and Kisbye Dreyer 2019; Steinberg et al. 2013). Dopamine is a key regulatory component of executive function in the prefrontal cortex, and dopaminergic dysfunction can result in impaired working memory (Klaus and Pennington 2019). In addition, dopamine dysfunction has been linked with the development of many psychiatric disorders. The symptoms and signs of schizophrenia have been linked to high levels of dopamine in specific areas of the brain and maintenance on antipsychotic drugs prevents relapse to a much greater extent than placebo up to 2 years of follow-up (Ceraso 2020; Seeman 2013). Recent studies show that dopaminergic receptor signaling is disrupted in dyskinetic Parkinsonian rats (Jones-Tabah, 2020) and dopamine is associated with prioritization of reward-associated memories in Parkinson's disease (Sharp et al. 2020). Restless legs syndrome and attention deficit hyperactivity disorder (ADHD) are also associated with decreased dopamine activity (Guo 2017; Volkow 2009).

ADHD is one of the most prevalent psychiatric disorders in children and adults, characterized by symptoms of inattention, hyperactivity, impulsivity, or combined type that produce impairment across cognitive, behavioral, and interpersonal domains (Kooij 2019). The results for some dopamine genes, such as dopamine receptor $\mathrm{D}_{4}$ and $\mathrm{D}_{5}$, dopamine transporter (DAT) and DBH confirm the heredity of ADHD syndromes (Paclt et al. 2005). Patients with ADHD showed a reduction in dopamine synaptic markers associated with symptoms of inattention as shown in the dopamine reward pathway of participants with ADHD (Volkow et al. 2009). Medin et al. (2013) report low dopamine $\mathrm{D}_{5}$ receptor density in hippocampus in an animal model of ADHD (Medin et al. 2013). Dopamine genes, its signaling and metabolism are linked with the pathophysiology of ADHD (Barkley et al. 2019).

ADHD patients often display circadian abnormalities including sleep problems (Coogan et al. 2016; Fisher et al. 2014; Gau et al. 2007). ADHD has been linked with disturbances in chronotype, particularly increased eveningness in children aged 7-12 years (Durmus et al. 2017). Patients with diagnosed ADHD show shorter average sleep durations (Boonstra et al. 2007) and frequent nocturnal awakenings (Sobanski et al. 2008).

Dopamine is involved in the regulation of sleep as regulator of the sleep/wake cycle, exerting a potent wake-promoting activity (Eban-Rothschild et al. 2018). In addition, dopamine is linked to circadian rhythmicity and extreme light sensitivity of circadian entrainment (Hirsh et al. 2010). Circadian molecular clock machinery mechanism consists of an interconnected series of transcriptional-translational feedback loops involving Circadian Locomotor Output Cycles Kaput (CLOCK) and Brain and Muscle Arnt-like Protein 1 (BMAL1) that heterodimerize and promote transcription of the Period (Per1/2/3) and Cryptochrome (Cryl/2) genes (Buhr and Takahashi 2013). Circadian rhythms are driven by the central pacemaker in the mammalian brain, the suprachiasmatic nucleus ( $\mathrm{SCN}$ ) of the hypothalamus, also entrained in peripheral cells including fibroblasts cultured in vitro (Balsalobre 1998; Schibler and Sassone-Corsi 2002). Our research group observed circadian gene alterations at the molecular level of human dermal fibroblasts derived from human individuals (ADHD and control subjects) (Coogan 2019). Human-derived fibroblasts provide an advantageous model to study circadian rhythmicity as well as the influence of drugs on circadian gene expression (Faltraco et al. 2020). Circadian clocks are linked with the regulation of neurotransmitter systems. Disruptions to these circadian clocks can effect cognitive functions in various diseases with altered neurotransmitter signalling (Kiehn et al. 2019).

Many essential psychiatric medications modulate the effects of dopamine, such as levodopa (L-DOPA) for Parkinson's Disease, and dopamine antagonists like antipsychotic and anti-nausea agents.

The psychostimulant methylphenidate and the selective norepinephrine transporter inhibitor atomoxetine, are two 
of the most frequently prescribed medications for ADHD. Methyphenidate blocks DAT, increasing levels of extracellular dopamine in the prefrontal cortex and striatum, as well as increasing concentrations of norepinephrine in the prefrontal cortex and hippocampus (Kuczenski and Segal 2002; Volkow 2001, 2002).

Atomoxetine increases extracellular levels of norepinephrine and dopamine in prefrontal cortex of rats, without effecting dopamine concentrations in striatum or nucleus accumbens (Bymaster 2002). Ide et al. observed that lowdose methylphenidate alters the reward system in wildtype mice via dopamine transporter inhibition. Dopamine transporter knockout mice do not exhibit such alterations. High-dose methylphenidate suppresses intracranial selfstimulation, suggesting the possibility that methylphenidate treatment does not increase the risk of drug dependence (Ide et al. 2018). Using HDF as a model, Coogan et al. (2019) report alterations in the expression of Per2 and Cryl between subjects with ADHD without medication, compared to ADHD subjects taking medication, or controls. Clock gene expression was also altered in pharmaceutically treated ADHD subjects. Analysis of fibroblasts transfected with a Bmall:luc reporter demonstrated changes in the timing of the peak expression across the three groups. Behavioral data that indicate that patients with ADHD using ADHD medication have lower relative amplitudes of diurnal activity rhythms, lower sleep efficiency and more nocturnal activity (Coogan et al. 2019).

Based on the assumption of the effectiveness of dopamine for the treatment of ADHD, its influence on the expression of the core circadian genes (Clock, Bmall, Perl-3, Cryl-2) is hypothesized. Therefore, in this study, the influence of dopamine on circadian rhythmicity are investigated in vitro.

\section{Materials and methods}

\section{Participant selection criteria}

Ethical approval for the conduct of the study, including obtaining human dermal biopsy samples, was given by the ethical review committee of Rostock University (Registration-number: A2013-159) and written consent was obtained from each study participant. The study was conducted according to the ethical guidelines of the Declaration of Helsinki.

ADHD patients and healthy controls participating in the study were recruited via the Department of Psychiatry and Psychotherapy, University Medical Centre Rostock. All ADHD patients were diagnosed by experienced psychiatrists in advance. The healthy control group was recruited of acquaintances of people involved in the study.
Human dermal fibroblasts (HDF) were obtained from skin biopsies from dorsal forearm from ADHD patients and healthy control volunteers. Only adult individuals, able to give informed consent, were included. Healthy controls without a history of childhood and adult ADHD were matched for sex and age. Patients with more severe than ADHD symptoms, were excluded, as were shift workers. Screening for ADHD symptoms was done by using the WURS-k (Wender Utah Rating Scale) as well as assessment of symptoms according to DSM-IV and ICD-10 criteria. Additional, the following psychometric tests were used to confirm ADHD diagnosis: SKIDI and II (Structured clinical interview), DIVA 2.0 (Structured diagnostic interview), CAARS (Conners' Adult ADHD Rating Scales) and PSQI (Pittsburgh Sleep Quality Index). The IQ of the healthy control group and volunteers with ADHD diagnosis were measured using MWT (Multiple-Choice Word Test). The chronotype of the participants were determined by the D-MEQ (Morning-Eveningness-Questionnaire, German Version). No special cognitive testing was implemented in the study.

Comorbidities were observed: $33.3 \%$ of participants with ADHD diagnosis has additionally adipositas, $8.3 \%$ has additionally addiction disorder, and $25.1 \%$ has additionally affective disorder. The remaining participants with ADHD diagnosis has no comorbidities.

The four manuscripts of this special issue dealing with circadian rhythmicity describe unique research questions (Faltraco et al. 2021a, b; Palm et al. 2021). Although some samples have been used for more than one research question, the overall sample composition differs from each other and thus is different for each study. Experiments differ substantially in their conditions, thus, they each investigate unique cellular biochemical pathways.

\section{Actigraphy}

To obtain objective measures of participants' sleep and circadian rhythm function, the rest-activity pattern of participants was recorded using wrist-worn actigraphs (Actiwatch 2, Philips Respironics, USA). Actigraphs were worn on the non-dominant wrist for a period of at least 7 consecutive days. The recording interval of the device was set at 60 -s epochs. Data occurring before the first and after the final midnight of each record were excluded, ensuring at least 6 complete days for each participant, with a complete weekend included in each record.

\section{Tissue isolation and fibroblast cell culture}

Human dermal fibroblasts (HDF) were isolated and cultured as described previously (Takashima 1998). Fibroblasts were cultivated $\left(37{ }^{\circ} \mathrm{C}, 5 \% \mathrm{CO}_{2}\right)$ in Dulbecco's Modified Eagle Medium DMEM (Gibco, Thermo Fisher, UK) $/ 1 \mathrm{mg} / \mathrm{ml}$ 
Liberase TM (Roche, Germany) containing 100 units/ml penicillin, $100 \mu \mathrm{g} / \mathrm{ml}$ streptomycin (Gibco, Thermo Fisher, UK) and 10\% fetal bovine serum FBS (Gibco, Thermo Fisher, UK).

\section{Measurement of cell viability}

Upon confluency of the respective primary fibroblast cell culture from each participant, cells were incubated with $0 \mu \mathrm{M}, 1 \mu \mathrm{M}$ and $10 \mu \mathrm{M}$ dopamine (Vitamaze, Germany). Following $24 \mathrm{~h}$ cell viability was measured using the Trypan Blue Exclusion Test (Strober 2015).

\section{Measurement of circadian gene expression}

Upon confluency of the respective primary fibroblast cell culture from each participant, eight culture flask replicates were prepared and cells were incubated with either $1 \mu \mathrm{M}$ or $10 \mu \mathrm{M}$ dopamine (Vitamaze, Germany). Cultures without dopamine were used as a negative control. After 24-h of incubation, the cells were synchronized with $100 \mathrm{nM}$ dexamethasone (Sigma-Aldrich, Germany) for $30 \mathrm{~min}$. Samples were harvested every fourth hour after synchronization for a period of 28-h in solution D (4.5 M guanidinium thiocyanate, $0,5 \%$ sodium- $\mathrm{N}$-lauryl sarcosine, $25 \mathrm{mM}$ tri-sodium citrate, $0.1 \mathrm{M}$ betamercaptoethanol) and stored at $-70{ }^{\circ} \mathrm{C}$. Total RNA was isolated and purified with RNeasy Plus Mini Kit (Qiagen, Germany) as well as subjected to reverse transcription using the Superscript III First-Strand Synthesis System (Invitrogen, Germany). Gene expression of Clock, Bmal1, Per1, Per2, Per3 and Cryl as well as housekeeping genes (Rpl13A, Rpl19A, GAPDH) was measured by realtime quantitative reverse transcriptase polymerase chain reaction (qRT-PCR) with CFX Connect ${ }^{\mathrm{TM}}$ Real-Time PCR Detection System (Biorad, Germany). The oligonucleotide sequences are presented in Table 1. All primers were purchased from Eurofins (Alameda, CA). The qRT-PCR was performed in 96-well 0.1-ml thin-wall PCR plates (Applied Biosystems) in the CFX Connect ${ }^{\mathrm{TM}}$ Real-Time PCR Detection System (Biorad, München, Germany) as previously described (Coogan 2019).

\section{Statistical methods}

Circadian gene expression data were tested for significant circadian rhythmicity, using CircWave v. 1.4 software (generated by Dr.Roelof Hut; www.euclock.org) to determine the best-fitting linear harmonic regression with an assumed period of 24-h and with $\alpha$ set at 0.05 . The center-of-gravity of each best-fitting waveform in CircWave was used as the circadian acrophase, and the associated estimation error was used as the SD. Inferential statistics were carried out in SPSS (IBM Corporation).

Actigraphic data were analyzed via MANCOVAs, with age, sex and in some cases ADHD symptom severity included in the model as co-variates.

qRT-PCR clock gene data were analyzed via ANOVA. For all inferential tests, $P<0.05$ was used to indicate a statistically significant groupwise difference. Sample sizes were calculated via GPower 3.1 software; for correlations, the assumptions used were significance level of $\alpha=0.05$ and the power of 0.8 for 2 groups (ADHD, HC) with 3 measures $(0 \mu \mathrm{M}, 1 \mu \mathrm{M}$ and $10 \mu \mathrm{M}$ dopamine). Although research in this field is generally scarce, we assumed that the influence of dopamine on the circadian gene expression will have an effect size $d^{\prime}=0.5$, returning a required total sample size of 21. Taking into consideration an expected drop-out rate, $n=12$ participants were allocated per each group. Data were analyzed via time series statistics adequately powered by 12 samples each, which in this statistical model is mathematically sufficient and thus representative (Menet et al. 2012; Thaben and Westermark 2016).
Table 1 Oligonucleotides for qRT-PCR to measure circadian gene expression

\begin{tabular}{lll}
\hline Gene & Forward primer $\left(5^{\prime}-3^{\prime}\right)$ & Reverse primer $\left(5^{\prime}-3^{\prime}\right)$ \\
\hline Clock & CCAGCAGTTTCATGAGATGC & GAGGTCATTTCATAGCTGAGC \\
Bmal1 & AAGGATGGCTGTTCAGCACATGA & CAAAAATCCATCTGCTGCCCTG \\
Per 1 & TGGGGACAACAGAACAGAGAA & AGGACACTCCTGCGACCA \\
Per 2 & GTATCCATTCATGCTGGGCT & TCGTTTGAACTGCGGTGAC \\
Per 3 & TCAGTGTTGGTGGAAGGAA & TCTGGGTCAGCAGCTCTACA \\
Cry1 & CACGAATCACAAACAGACGG & TACATCCTGGACCCTGGT \\
RPL13a & GCCAGAAATGTTGATGCCTT & AGATGGCGGAGGTGCAG \\
RPL19a & GTGGCAAGAAGAAGGTCTGG & GCCCATCTTTGATGAGCTTC \\
GAPDH & GAAGGTGAAGGTCGGAGT & GAAGATGGTGATGGGATTTC \\
\hline
\end{tabular}




\section{Results}

\section{Demographic data}

Human dermal fibroblasts (HDF) were obtained via skin biopsy from volunteers with attention deficit hyperactivity disorder (ADHD) ( 8 men, 4 women; $45.08 \pm 18.07$ years, mean $\pm \mathrm{SD}$; BMI: $26.73 \pm 4.48 \mathrm{~kg} / \mathrm{m}^{2}$, mean $\left.\pm \mathrm{SD}\right)$, matched by healthy controls (HC) (4 men, 8 women; $41.50 \pm 14.04$ years, mean \pm SD; BMI: $25.87 \pm 5.42 \mathrm{~kg} /$ $\mathrm{m}^{2}$, mean $\pm \mathrm{SD}$ ). All participants completed the Multiple-Choice Word Test (IQ score: ADHD participants: $107.50 \pm 10.91$, mean \pm SD, HC: $110.25 \pm 9.32$, mean \pm SD), Morningness-Eveningness-Questionnaire, German Version (D-MEQ Score: ADHD participants: $44.33 \pm 16.14$, mean \pm SD, HC: $58.83 \pm 8.97$, mean \pm SD, $p<0.01)$ and Wender Utah Rating Scale, German Short Version (WURS-k Score: ADHD participants: $41.50 \pm 14.94$, mean \pm SD; HC: $7.17 \pm 8.19$, mean \pm SD, $p<0.0001)$. The demographic data are presented in Table 2.

There were no significant differences in age, BMI, IQ or gender across the two study groups. D-MEQ scores indicated that ADHD patients displayed more definitive and moderate evening preference than HC. 58.3\% of healthy participants displayed neutral preferences, whereas $25.0 \%$ had moderate morning preference, and $16.7 \%$ definite morning preference. $25.0 \%$ of ADHD participants displayed moderate morning preference, and $33.3 \%$ neutral preference. In the ADHD group the evening preference was represented by $25.0 \%$ definite evening and $16.7 \%$ moderate evening type. There were no participants with definitive morning preference in the ADHD group.

\section{Actigraphy}

Measures from the non-parametric circadian rhythm analysis were analyzed across the two groups, healthy controls and ADHD participants, in a MANCOVA with age and sex

Table 2 Demographic data

\begin{tabular}{lll}
\hline Demographic data & Healthy controls $n=12$ & ADHD $n=12$ \\
\hline Age & $41.50 \pm 14.04$ years & $45.08 \pm 18.07$ years \\
Female & $8(66.7 \%)$ & $4(33.3 \%)$ \\
BMI & $25.87 \pm 5.42$ & $26.73 \pm 4.48$ \\
IQ-Score & $110.25 \pm 9.32$ & $107.50 \pm 10.91$ \\
D-MEQ & $58.83 \pm 8.97 * *$ & $44.33 \pm 16.14 * *$ \\
WURS-k-Score & $7.17 \pm 8.19 * * *$ & $41.50 \pm 14.94 * * *$ \\
\hline
\end{tabular}

$* p<0.01, * * * p<0.001$ as co-variates. No statistically significant effect of group was observed (Pillai's trace $=0.380 ; F=1.226 ; P=0.359$; partial ETA squared $=0.380)$. No significant difference for mid-sleep on weekend days $(p=0.774)$, mid-sleep on weekdays $(p=0.169)$, social jetlag $(p=0.984)$, sleep efficiency $(p=0.833)$, WASO (wakening after sleep onset; $p=0.844)$ and total number of wake bouts $(p=0.425)$ was shown (Fig. 1). The measurements for three ADHD volunteers were not completed.

\section{Cell viability}

The viability of the cultivated human dermal fibroblasts (HDF) after dopamine incubation was compared with HDFs without dopamine. The viability of cells treated with Dopamine ( $1 \mu \mathrm{M}$ Dopamine: $91.067 \pm 0.007$, mean \pm SD; $10 \mu \mathrm{M}$ Dopamine: $90.204 \pm 0.002$, mean \pm SD) was higher than compared to control cells without dopamine ( $0 \mu \mathrm{M}$ Dopamine: $83.650 \pm 0.009$, mean $\pm S D)$. After incubation with dopamine the cell numbers increased by $147 \%$ for $1 \mu \mathrm{M}$ Dopamine and $154 \%$ for $10 \mu \mathrm{M}$ Dopamine, compared to the cells without dopamine.

\section{Circadian gene expression in human dermal fibroblasts}

The expression profiles of circadian genes after incubation with $1.0 \mu \mathrm{M}$ and $10.0 \mu \mathrm{M}$ dopamine concentrations were examined in primary fibroblasts cultured from skin biopsies collected from ADHD and healthy participants and synchronized with dexamethasone. Cultures without dopamine were used as a negative control.

Bmall, Cryl and Per3 expression was strongly rhythmic in both groups (CircWave, $p<0.001$ ). No rhythmicity was detected for Clock in both groups except for cultures incubated with $1 \mu \mathrm{M}$ dopamine (CircWave, $p<0.05$ ). In the ADHD group, $10 \mu \mathrm{M}$ dopamine exposure dampened the rhythmicity of Clock (CircWave, $p>0.05$ ). The same effect was observed for Perl/2 genes in cultures from healthy controls (HC) (CircWave, $p>0.05$ ). Dopamine shifted the Clock circadian acrophase to $20.00 \pm 3.37 \mathrm{~h}$ (CircWave, mean $\pm \mathrm{SD}$ ) compared to $5.68 \pm 3.37 \mathrm{~h}$ (CircWave, mean $\pm \mathrm{SD}$ ) in cultures without dopamine. In the ADHD group exposure to dopamine shifted the Perl circadian acrophase to $5.63 \pm 2.22 \mathrm{~h}$ (CircWave, mean $\pm \mathrm{SD}$ ) compared to $7.07 \pm 2.09 \mathrm{~h}$ (CircWave, mean $\pm \mathrm{SD}$ ) in cultures without dopamine.

Differences of clock gene expression levels among study groups were assessed using one-way ANOVA (Fig. 2). When comparing the two study groups, ADHD and HC, one-way ANOVA revealed significant different Per2 at ZT4 $(p=0.003, F=4.075)$ and Cryl at ZT28 $(p=0.002$, $F=4.451)$. A Bonferroni post hoc correction revealed a 

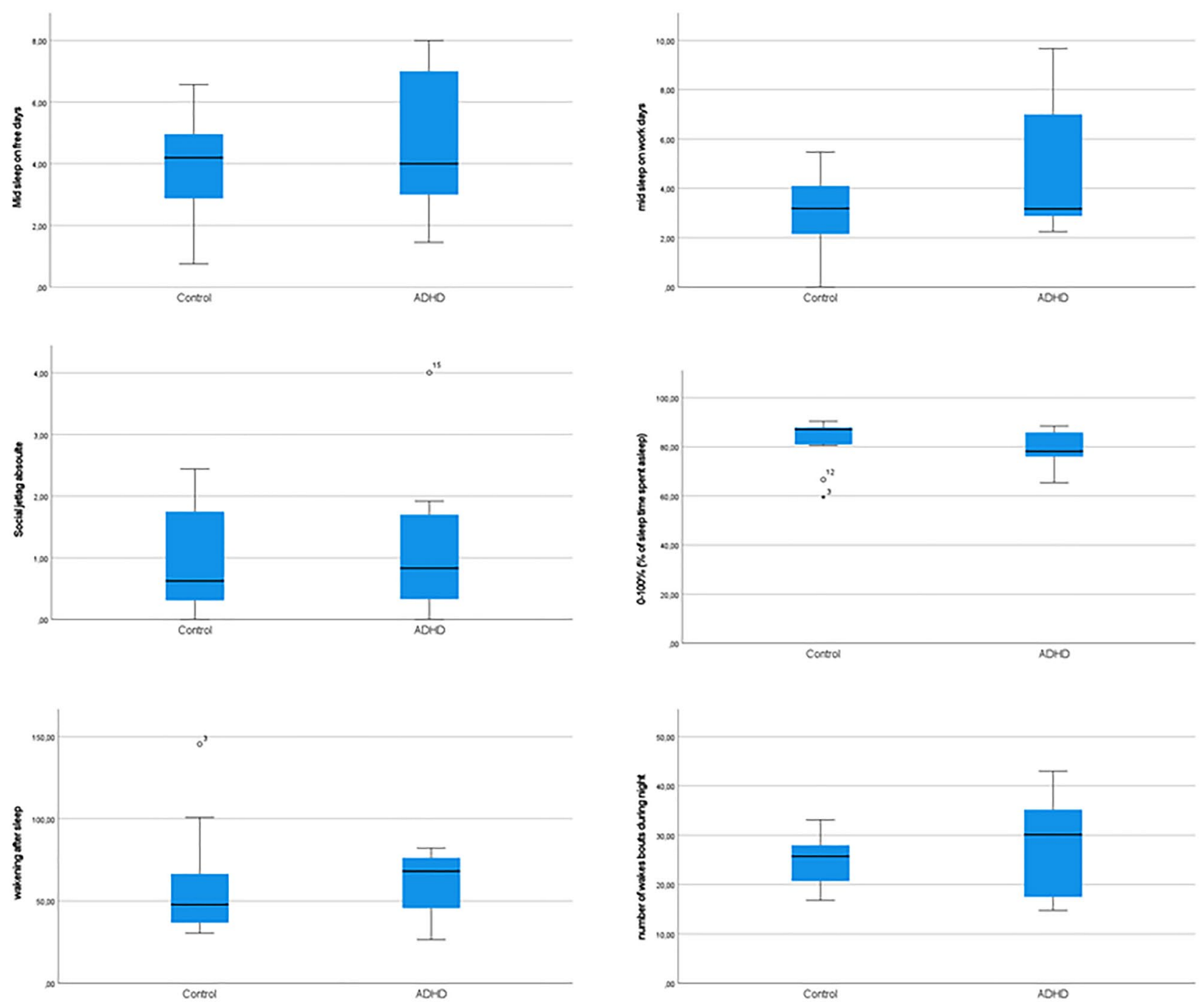

Fig. 1 Actigraphic measures of mid-sleep of weekend days, mid-sleep of week days social jetlag, sleep efficiency, WASO (wakening after sleep onset) and total number of wake bouts are displayed as boxplots. Circles correspond to outer values and asterisks correspond to extreme values

significant different expression of Per2 (ZT4, $p=0.011)$ between the $\mathrm{HC}$ and ADHD cultures incubated with $10 \mu \mathrm{M}$ dopamine. The expression and rhythm of Per2 gene in the ADHD group resulted in an adjustment to the HC group after $10 \mu \mathrm{M}$ dopamine incubation (Fig. 3). The expression of Cryl (ZT 28, $p=0.001$ ) was different between HC and ADHD without dopamine incubation.

Gene expression in healthy participants revealed a statistical significant difference between cultures incubated with dopamine and negative controls (without dopamine incubation), as determined by one-way ANOVA for Cryl at ZT28 $(F=5.594, p=0.008)$ and Per2 at ZT4 $(p=0.043$, $F=3.473$ ). A Bonferroni post hoc correction revealed a significant lower Cryl expression in cultures incubated with $1 \mu \mathrm{M}$ dopamine $(p=0.019)$ and $10 \mu \mathrm{M}$ dopamine $(p=0.018)$ compared to HDF cultures without dopamine. $10 \mu \mathrm{M}$ dopamine significant lowered the expression levels of Per 2 at ZT4 $(p=0.040)$ compared to the cultures without dopamine. Oneway ANOVA revealed in the ADHD group statistical significant Per 2 expression at the same time-point, ZT4 $(p=0.024$, $F=4.170$ ) between samples incubated with $1 \mu \mathrm{M}$ and $10 \mu \mathrm{M}$ dopamine. In the ADHD group, statistical significant differences were observed at ZT24 and ZT28 between cultures incubated with dopamine and negative controls, particularly, for period genes Perl (ZT28, $F=5.103, p=0.012$ ) and Per3 (ZT24, $F=7.703, p=0.002$; ZT28, $F=3.800, p=0.033$ ). A Bonferroni post hoc correction revealed a significant higher expression of Perl at ZT28 in cultures incubated with $1 \mu \mathrm{M}$ dopamine $(p=0.049)$ and $10 \mu \mathrm{M}$ dopamine $(p=0.016)$ compared to negative controls. The same effect was observed for 




BMALI



Oh 4 h 8 h 12 h 16 h 20 h 24 h28h
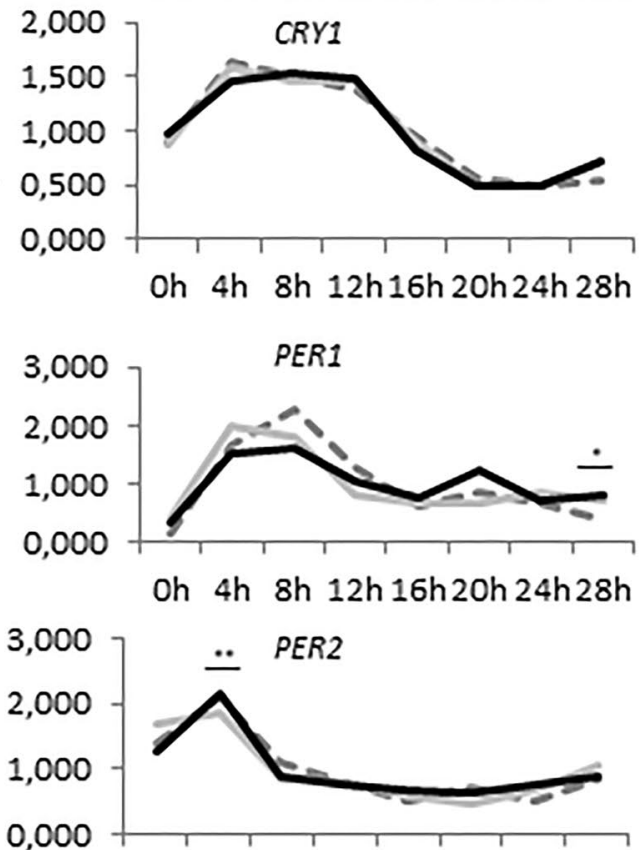

Oh $4 \mathrm{~h} 8 \mathrm{~h} 12 \mathrm{~h} 16 \mathrm{~h} 2 \mathrm{Oh} 24 \mathrm{~h} 28 \mathrm{~h}$

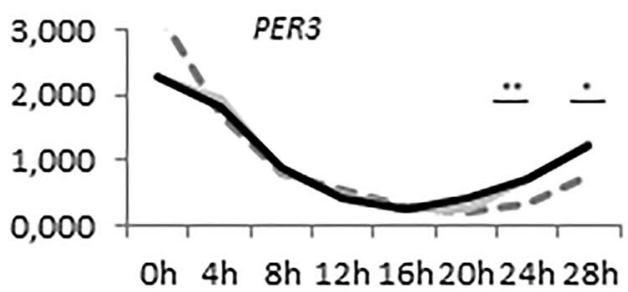

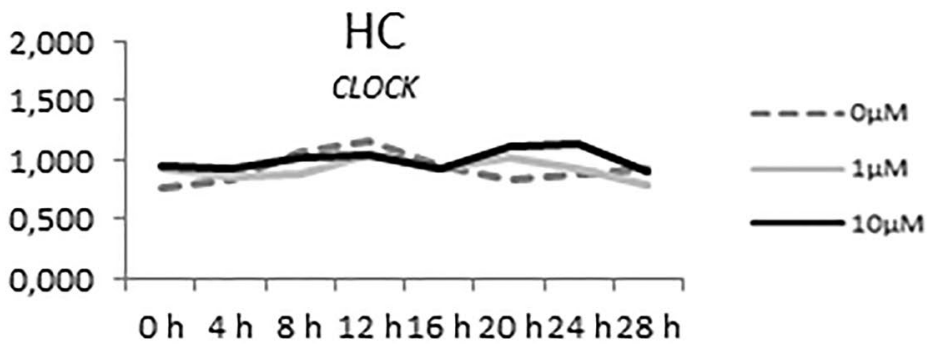

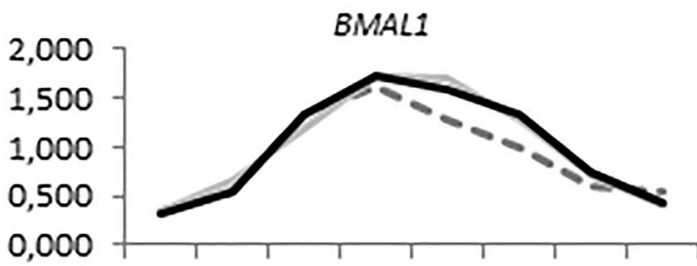

$\mathrm{Oh} 4 \mathrm{~h} 8 \mathrm{~h} 12 \mathrm{~h} 16 \mathrm{~h} 20 \mathrm{~h} 24 \mathrm{~h} 28 \mathrm{~h}$

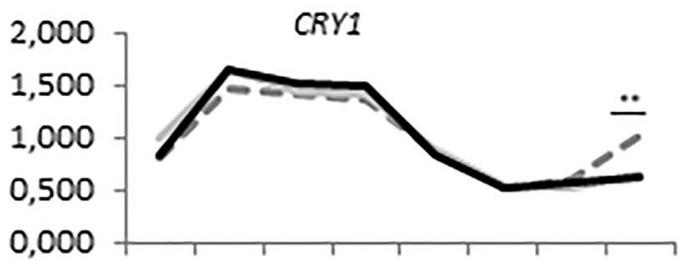

Oh $4 \mathrm{~h} 8 \mathrm{~h} 12 \mathrm{~h} 16 \mathrm{~h}$ 20h $24 \mathrm{~h} 28 \mathrm{~h}$
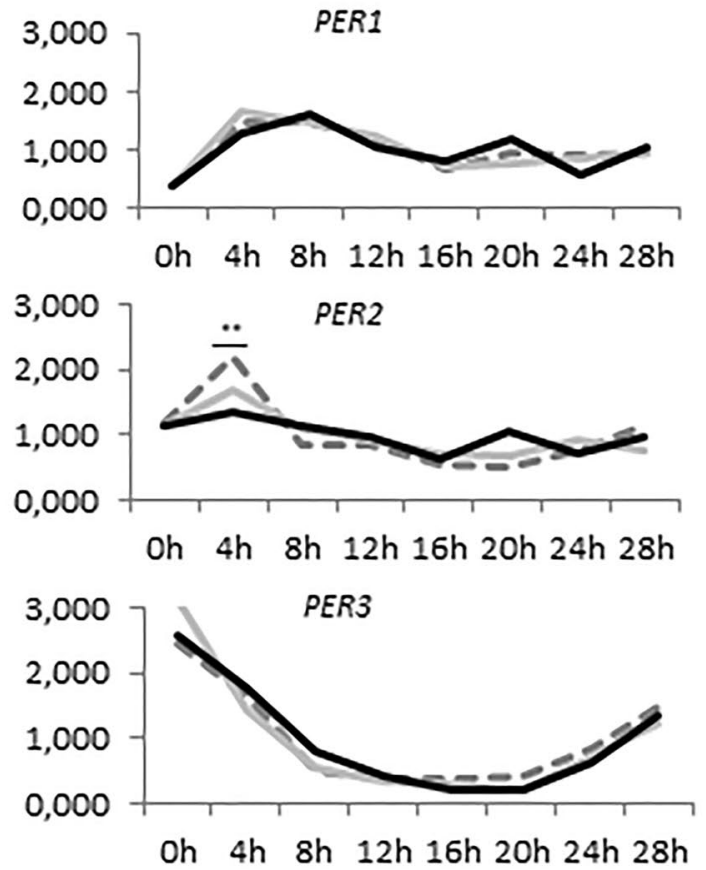

\section{Time after synchronisation (h)}

Fig. 2 Relative mRNA gene expression of circadian genes in healthy controls and ADHD volunteers $\left(0,1.0,10.0 \mu \mathrm{M}\right.$ Dopamine). ${ }^{*} p<0.05$, $* * p<0.01$

Per3 gene expression for the cultures incubated with $1 \mu \mathrm{M}$ dopamine (ZT28, $p=0.039) .1 \mu \mathrm{M}(p=0.003)$ and $10 \mu \mathrm{M}$ $(p=0.010)$ dopamine increased the expression of Per3 at ZT24 compared to the negative controls.

\section{Discussion}

In the present study, the incubation of human dermal fibroblast cultures with $1 \mu \mathrm{M}$ dopamine induced the 

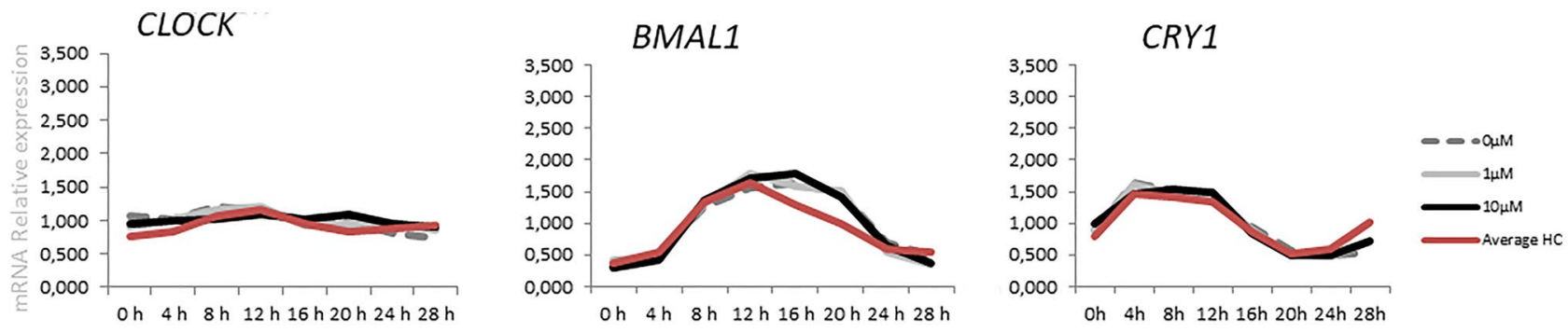

PER1

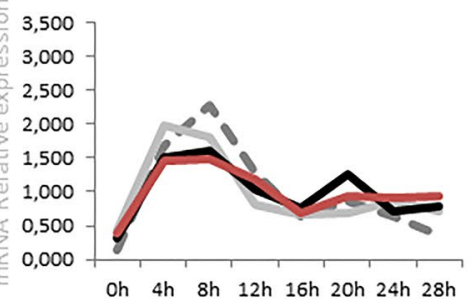

PER2

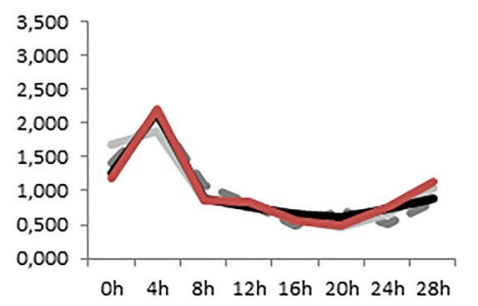

PER3

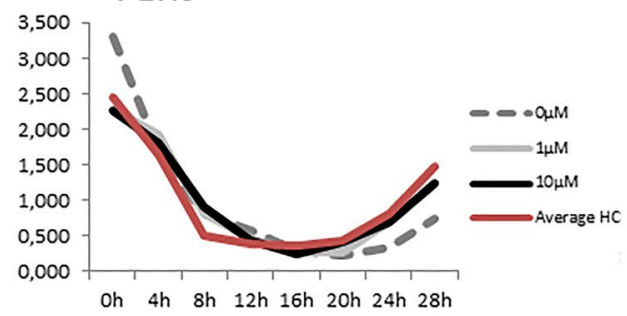

Fig. 3 Relative mRNA gene expression of circadian genes in healthy controls $(0 \mu \mathrm{m})$ and ADHD volunteers $(0,1.0,10.0 \mu \mathrm{M}$ Dopamine $)$

rhythmicity of Clock gene. This effect was not observed in cultures incubated with 0 and $10 \mu \mathrm{M}$ dopamine. Preliminary results from our work has shown that Clock gene rhythmicity is also linked with the neurotransmitter norepinephrine. Norepinephrine is a known synchronizer of the circadian rhythm ( $\mathrm{Li}$ and Cassone 2015; Maletic et al. 2017). This effect could suggest a potential link between the monoamines neurotransmitters and circadian rhythm pathways.

Hirsh et al. observed that dopamine plays an important role in the circadian behavior of Drosophila melanogaster. These drosophila mutants lacking tyrosine hydroxylase neural expression show weak circadian rhythmicity. The tyrosine hydroxylase rescue strain, deficient in neural dopamine also selectively shows a defect in circadian entrainment to low light levels (Hirsh et al. 2010). Under a light-dark cycle, tyrosine hydroxylase exhibited rhythmic patterns of transcription in chicken embryonic retinal cells (Lima et al. 2011). Low levels of dopamine also were observed in zebrafish mutants for the circadian gene periodlb (Huang et al. 2015). These zebrafish mutants display hyperactivity, impulsivity-like and inattention-like behavior. Huang et al. found that the circadian clock regulates dopamine-related genes dopamine $\beta$ hydroxylase and MAO. MAO is rhythmically expressed in wild-type larvae and upregulated in per $1 b$ mutant larvae (Huang et al. 2015). Kim et al. studied the influence of Per 2 in cases of methamphetamine addiction and observed that Per2-overexpressed mice presented lower dopamine levels compared to Per2-knockout mice, suggesting that Per2 may influence the addictive effects of methamphetamine through the dopaminergic system (Kim, 2019). Bussi et al. studied interval timing (duration discrimination within the seconds-to-minutes range), which involves the dopaminergic-glutamatergic pathway. The authors suggested that the lack of dopamine rhythmicity under constant light is probably regulated by Per 2 and this could be responsible for impaired performance in the timing task in the mice model organism (Bussi et al. 2014). Hood et al. demonstrated a direct relationship between extracellular dopamine levels and the rhythm of expression of the clock protein PERIOD2 (PER2) in the dorsal striatum in male Wistar rat. The authors suggested that the rhythm of expression of PER2 depends on daily dopaminergic activation of $\mathrm{D}(2)$ dopamine receptors (Hood, 2010).

The study of Yokokura et al. suggests that microglial activation and dopamine D1 receptor reduction, as well as their aberrant interactions underpin the neurophysiological mechanism of ADHD (Yokokura, 2020). Volkow et al. demonstrated that a reduction in dopamine synaptic markers are associated with symptoms of inattention in the dopamine reward pathway of participants with ADHD. The D2/ D3 receptor measures were correlated with attention implicating the dopamine reward pathway in the symptoms of inattention in ADHD (Volkow et al. 2009). Previous studies focused on genetics and environmental etiologies also proposed a relation between dopamine and ADHD (Braun et al. 2006; Swanson, 2007). Imaging studies observed that brain dopamine neurotransmission is disrupted in ADHD (Ernst 
et al. 1999; Lou et al. 2004; Rosa Neto et al. 2002; Volkow et al. 2007a, b).

To the best of our knowledge, until now, no studies have analyzed the influence of dopamine in human fibroblast cell cultures of healthy controls and volunteers with ADHD. The results of the present study illustrate that ADHD leads to alterations in the circadian rhythm. It demonstrates that dopamine impacts on circadian function, particularly the Cryl, Perl/2/3 gene expression.

Dopamine showed no effect on Per3 expression in healthy controls, but exhibited a significant difference in the ADHD group at ZT24 and ZT28 compared to samples without dopamine incubation. Incubation with dopamine, either $1 \mu \mathrm{M}$ or $10 \mu \mathrm{M}$, result in an adjustment of Per3 expression to the healthy controls (without dopamine incubation). Additionally, dopamine significantly reduces the Per 2 expression in cells of healthy controls. In the ADHD group, dopamine incubation results in an adjustment of Per2 expression to healthy controls without dopamine incubation. These results lead to the suggestion that dopamine may improve the sleep quality as well as ADHD symptoms by adjustment of the circadian gene expression, especially for Per2 and Per3.

It is to mention, that no special cognitive testing was implemented in this study. In addition, the participants of the ADHD group took no medication during the study. For further studies, a connection between circadian disturbances, cognitive deficits and the effect of medication would be suitable.

Acknowledgements 2020 CoCA ADHD Comorbidity. This project has received funding from the European Union's Horizon 2020 research and innovation programme under grant agreement No 667302.

Funding Open Access funding enabled and organized by Projekt DEAL. 2020 CoCA ADHD Comorbidity. This project has received funding from the European Union's Horizon 2020 research and innovation programme under grant agreement No 667302.

Code availability Actiwatch 2, Philips Respironics, USA; CircWave v. 1.4 software (generated by Dr. Roelof Hut; www.euclock.org); SPSS (IBM Corporation)

\section{Declarations}

Conflict of interest Johannes Thome has received financial support from pharmaceutical companies (Actelion, Astra Zeneca, BristolMyers Squibb, EVER Neuro Pharma GmbH, Janssen-Cilag, Lilly, Lundbeck, MEDICE, Merz, Novartis, Pfizer, Roche, Servier, Shire, Trommsdorff) some of which manufacture medication used in the treatment of ADHD patients. Frank Faltraco, Oliver Tucha, Frederick Simon, Adriana Uzoni, Lena Borchert and Denise Palm have no potential conflicts of interest to disclose.

Ethics approval Ethical approval for the conduct of the study, including obtaining human dermal biopsy samples, was given by the ethical review committee of Rostock University (Registration-number: A2013-159).
Consent to participate Written consent was obtained from each study participant.

Consent for publication Written consent was obtained from each study participant.

Open Access This article is licensed under a Creative Commons Attribution 4.0 International License, which permits use, sharing, adaptation, distribution and reproduction in any medium or format, as long as you give appropriate credit to the original author(s) and the source, provide a link to the Creative Commons licence, and indicate if changes were made. The images or other third party material in this article are included in the article's Creative Commons licence, unless indicated otherwise in a credit line to the material. If material is not included in the article's Creative Commons licence and your intended use is not permitted by statutory regulation or exceeds the permitted use, you will need to obtain permission directly from the copyright holder. To view a copy of this licence, visit http://creativecommons.org/licenses/by/4.0/.

\section{References}

Awata H, Watanabe T, Hamanaka Y, Mito T, Noji S, Mizunami M (2015) Knockout crickets for the study of learning and memory: Dopamine receptor Dop1 mediates aversive but not appetitive reinforcement in crickets. Sci Rep 5:15885. https://doi.org/10. 1038/srep 15885

Balsalobre ADF, Schibler U (1998) A serum shock induces circadian gene expression in mammalian tissue culture cells. Cell 93:929-937

Barkley RA, Smith KM, Fischer M (2019) ADHD risk genes involved in dopamine signaling and metabolism are associated with reduced estimated life expectancy at young adult follow-up in hyperactive and control children. Am J Med Genet B Neuropsychiatr Genet 180:175-185. https://doi.org/10.1002/ajmg.b. 32711

Beaulieu JM, Espinoza S, Gainetdinov RR (2015) Dopamine receptors - IUPHAR Review. Br J Pharmacol 172:1-23. https://doi. org/10.1111/bph.12906

Beeler JA, Kisbye Dreyer J (2019) Synchronicity: The Role of Midbrain Dopamine in Whole-Brain Coordination. eNeuro. https:// doi.org/10.1523/ENEURO.0345-18.2019

Blenau W, Baumann A (2001) Molecular and pharmacological properties of insect biogenic amine receptors: lessons from Drosophila melanogaster and Apis mellifera. Arch Insect Biochem Physiol 48:13-38. https://doi.org/10.1002/arch.1055

Boonstra AM, Kooij JJ, Oosterlaan J, Sergeant JA, Buitelaar JK, Van Someren EJ (2007) Hyperactive night and day? Actigraphy studies in adult ADHD: a baseline comparison and the effect of methylphenidate. Sleep 30:433-442

Braun JM, Kahn RS, Froehlich T, Auinger P, Lanphear BP (2006) Exposures to environmental toxicants and attention deficit hyperactivity disorder in U.S. children. Environ Health Perspect 114:1904-1909. https://doi.org/10.1289/ehp.9478

Buhr ED, Takahashi JS (2013) Molecular components of the Mammalian circadian clock. Handb Exp Pharmacol. https://doi.org/ 10.1007/978-3-642-25950-0

Bussi IL, Levin G, Golombek DA, Agostino PV (2014) Involvement of dopamine signaling in the circadian modulation of interval timing. Eur J Neurosci 40:2299-2310. https://doi.org/10.1111/ejn.12569

Bymaster JS, Nelson DL, Hemrick-Luecke SK, Threlkeld PG, Heiligenstein JH, Morin SM, Gehlert DR, Perry KW (2002) Atomoxetine 
increases extracellular levels of norepinephrine and dopamine in prefrontal cortex of rat. Neuropsychopharmacology 27:699-711

Cahill AL, Ehret CF (1981) Circadian variations in the activity of tyrosine hydroxylase, tyrosine aminotransferase, and tryptophan hydroxylase: relationship to catecholamine metabolism. J Neurochem 37:1109-1115. https://doi.org/10.1111/j.1471-4159.1981. tb04660.x

Catelas DN, Serrao MP, Soares-Da-Silva P (2020) Effects of nepicastat upon dopamine-beta-hydroxylase activity and dopamine and norepinephrine levels in the rat left ventricle, kidney, and adrenal gland. Clin Exp Hypertens 42:118-125. https://doi.org/10.1080/ 10641963.2019.1583245

Ceraso A et al (2020) Maintenance treatment with antipsychotic drugs for schizophrenia. Cochrane Database Syst Rev 8:CD008016. https://doi.org/10.1002/14651858.CD008016.pub3

Coogan AN, Baird AL, Popa-Wagner A, Thome J (2016) Circadian rhythms and attention deficit hyperactivity disorder: the what, the when and the why. Prog Neuropsychopharmacol Biol Psychiatry 67:74-81. https://doi.org/10.1016/j.pnpbp.2016.01.006

Coogan AN et al (2019) Impact of adult attention deficit hyperactivity disorder and medication status on sleep/wake behavior and molecular circadian rhythms. Neuropsychopharmacology 44:1198-1206. https://doi.org/10.1038/s41386-019-0327-6

Durmus FB, Arman AR, Ayaz AB (2017) Chronotype and its relationship with sleep disorders in children with attention deficit hyperactivity disorder. Chronobiol Int 34:886-894. https://doi.org/10. 1080/07420528.2017.1329207

Eban-Rothschild A, Appelbaum L, de Lecea L (2018) Neuronal mechanisms for sleep/wake regulation and modulatory drive. Neuropsychopharmacology 43:937-952. https://doi.org/10.1038/npp.2017. 294

Eisenhofer G, Kopin IJ, Goldstein DS (2004) Catecholamine metabolism: a contemporary view with implications for physiology and medicine. Pharmacol Rev 56:331-349. https://doi.org/10.1124/ pr.56.3.1

Eldadah MK, Schwartz PH, Harrison R, Newth CJ (1991) Pharmacokinetics of dopamine in infants and children. Crit Care Med 19:1008-1011. https://doi.org/10.1097/00003246-19910 8000-00006

Ernst M, Zametkin AJ, Matochik JA, Pascualvaca D, Jons PH, Cohen RM (1999) High midbrain [18F]DOPA accumulation in children with attention deficit hyperactivity disorder. Am J Psychiatry 156:1209-1215. https://doi.org/10.1176/ajp.156.8.1209

Faltraco F, Uzoni A, Shevchuk L, Thome J, Palm D (2020) Synchronization of fibroblasts ex vivo in psychopharmacology. Pharmacopsychiatry. https://doi.org/10.1055/a-1151-4947

Faltraco F, Palm D, Uzoni A, Simon F, Tucha O, Thome J (2021a) Atomoxetine and circadian gene expression in human dermal fibroblasts from participants with a diagnosis of attention-deficit hyperactivity disorder. J Neural Transm. https://doi.org/10.1007/ s00702-021-02373-5 (Accepted)

Faltraco F, Palm D, Coogan A, Uzoni A, Duwe I, Simon F, Tucha O, Thome J (2021b) Remdesivir shifts circadian rhythmicity to eveningness; similar to the most prevalent chronotype to ADHD. J Neural Transm. https://doi.org/10.1007/s00702-021-02375-3 (Accepted)

Farzam K, Kidron A, Lakhkar AD (2020) Adrenergic drugs. In: StatPearls. Treasure Island (FL)

Fisher BC, Garges DM, Yoon SY, Maguire K, Zipay D, Gambino M (2009) Shapiro CM (2014) Sex differences and the interaction of age and sleep issues in neuropsychological testing performance across the lifespan in an ADD/ADHD sample from the years 1989 to. Psychol Rep 114:404-438. https://doi.org/10.2466/15.10.PR0. $114 \mathrm{k} 23 \mathrm{w} 0$

Gau SS, Kessler RC, Tseng WL, Wu YY, Chiu YN, Yeh CB, Hwu HG (2007) Association between sleep problems and symptoms of attention-deficit/hyperactivity disorder in young adults. Sleep 30:195-201. https://doi.org/10.1093/sleep/30.2.195

Guo $S$ et al (2017) Restless legs syndrome: from pathophysiology to clinical diagnosis and management. Front Aging Neurosci 9:171. https://doi.org/10.3389/fnagi.2017.00171

Hirsh J, Riemensperger T, Coulom H, Iche M, Coupar J, Birman S (2010) Roles of dopamine in circadian rhythmicity and extreme light sensitivity of circadian entrainment. Curr Biol 20:209-214. https://doi.org/10.1016/j.cub.2009.11.037

Hood S et al (2010) Endogenous dopamine regulates the rhythm of expression of the clock protein PER2 in the rat dorsal striatum via daily activation of D2 dopamine receptors. J Neurosci 30:1404614058. https://doi.org/10.1523/JNEUROSCI.2128-10.2010

Huang $\mathbf{J}$ et al (2015) Circadian modulation of dopamine levels and dopaminergic neuron development contributes to attention deficiency and hyperactive behavior. J Neurosci 35:2572-2587. https://doi.org/10.1523/JNEUROSCI.2551-14.2015

Ide S, Ikekubo Y, Hua J, Takamatsu Y, Uhl GR, Sora I, Ikeda K (2018) Reward-enhancing effect of methylphenidate is abolished in dopamine transporter knockout mice: A model of attention-deficit/ hyperactivity disorder. Neuropsychopharmacol Rep 38:149-153. https://doi.org/10.1002/npr2.12020

Jones-Tabah J et al (2020) Dopamine D1 receptor signalling in dyskinetic Parkinsonian rats revealed by fiber photometry using FRET-based biosensors. Sci Rep 10:14426. https://doi.org/10. 1038/s41598-020-71121-8

Kiehn JT, Faltraco F, Palm D, Thome J, Oster H (2019) Circadian clocks in the regulation of neurotransmitter systems. Pharmacopsychiatry. https://doi.org/10.1055/a-1027-7055

Kim M et al (2019) The circadian gene, Per2, influences methamphetamine sensitization and reward through the dopaminergic system in the striatum of mice. Addict Biol 24:946-957. https://doi.org/ 10.1111/adb. 12663

Klaus K, Pennington K (2019) Dopamine and working memory: genetic variation, stress and implications for mental health. Curr Top Behav Neurosci 41:369-391. https://doi.org/10.1007/7854_ 2019_113

Kooij JJS et al (2019) Updated European consensus statement on diagnosis and treatment of adult ADHD. Eur Psychiatry 56:1434. https://doi.org/10.1016/j.eurpsy.2018.11.001

Kuczenski R, Segal DS (2002) Exposure of adolescent rats to oral methylphenidate: preferential effects on extracellular norepinephrine and absence of sensitization and cross-sensitization to methamphetamine. J Neurosci 22:7264-7271

Li Y, Cassone VM (2015) Clock-controlled regulation of the acute effects of norepinephrine on chick pineal melatonin rhythms. J Biol Rhythms 30:519-532. https://doi.org/10.1177/0748730415 607060

Lima LH, Santos KP, Lauro Castrucci AM (2011) Clock genes, melanopsins, melatonin, and dopamine key enzymes and their modulation by light and glutamate in chicken embryonic retinal cells. Chronobiol Int 28:89-100. https://doi.org/10.3109/07420 528.2010.540685

Lou HC, Rosa P, Pryds O, Karrebaek H, Lunding J, Cumming P, Gjedde A (2004) ADHD: increased dopamine receptor availability linked to attention deficit and low neonatal cerebral blood flow. Dev Med Child Neurol 46:179-183. https://doi.org/10. 1017/s0012162204000313

MacGregor DA, Smith TE, Prielipp RC, Butterworth JF, James RL, Scuderi PE (2000) Pharmacokinetics of dopamine in healthy male subjects. Anesthesiology 92:338-346. https://doi.org/10. 1097/00000542-200002000-00013

Maletic V, Eramo A, Gwin K, Offord SJ, Duffy RA (2017) The role of norepinephrine and its alpha-adrenergic receptors in the pathophysiology and treatment of major depressive disorder 
and schizophrenia: a systematic review. Front Psychiatry 8:42. https://doi.org/10.3389/fpsyt.2017.00042

McHugh PC, Buckley DA (2015) The structure and function of the dopamine transporter and its role in CNS diseases. Vitam Horm 98:339-369. https://doi.org/10.1016/bs.vh.2014.12.009

Medin T, Rinholm JE, Owe SG, Sagvolden T, Gjedde A, StormMathisen J, Bergersen LH (2013) Low dopamine D5 receptor density in hippocampus in an animal model of attention-deficit/hyperactivity disorder (ADHD). Neuroscience 242:11-20. https://doi.org/10.1016/j.neuroscience.2013.03.036

Meiser J, Weindl D, Hiller K (2013) Complexity of dopamine metabolism. Cell Commun Signal 11:34. https://doi.org/10. 1186/1478-811X-11-34

Menet JS, Rodriguez J, Abruzzi KC, Rosbash M (2012) Nascentseq reveals novel features of mouse circadian transcriptional regulation. Elife 1:e00011. https://doi.org/10.7554/eLife.00011

Paclt I, Koudelova J, Krepelova A, Uhlikova P, Gazdikova M, Bauer P (2005) Biochemical markers and genetic research of ADHD. Neuro Endocrinol Lett 26:423-430

Padbury JF, Agata Y, Baylen BG, Ludlow JK, Polk DH, Habib DM, Martinez AM (1990) Pharmacokinetics of dopamine in critically ill newborn infants. J Pediatr 117:472-476. https://doi. org/10.1016/s0022-3476(05)81101-1

Palm D, Uzoni A, Simon F, Tucha F, Thome J, Faltraco F (2021) Norepinephrine influences the circadian clock in human dermal fibroblasts from participants with a diagnosis of attention deficit hyperactivity disorder. J Neural Transm. https://doi.org/10. 1007/s00702-021-02376-2 (Accepted)

Roeder T (2002) Biochemistry and molecular biology of receptors for biogenic amines in locusts. Microsc Res Tech 56:237-247. https://doi.org/10.1002/jemt.10027

Rosa Neto P, Lou H, Cumming P, Pryds O, Gjedde A (2002) Methylphenidate-evoked potentiation of extracellular dopamine in the brain of adolescents with premature birth: correlation with attentional deficit. Ann N Y Acad Sci 965:434-439. https://doi. org/10.1111/j.1749-6632.2002.tb04184.x

Salatino-Oliveira A, Rohde LA, Hutz MH (2018) The dopamine transporter role in psychiatric phenotypes. Am J Med Genet B Neuropsychiatr Genet 177:211-231. https://doi.org/10.1002/ajmg.b. 32578

Schibler U, Sassone-Corsi P (2002) A web of circadian pacemakers. Cell 111:919-922. https://doi.org/10.1016/s0092-8674(02) 01225-4

Seeman P (2013) Schizophrenia and dopamine receptors. Eur Neuropsychopharmacol 23:999-1009. https://doi.org/10.1016/j.euron euro.2013.06.005

Sharp ME, Duncan K, Foerde K, Shohamy D (2020) Dopamine is associated with prioritization of reward-associated memories in Parkinson's disease. Brain 143:2519-2531. https://doi.org/10. 1093/brain/awaa182

Sobanski E, Schredl M, Kettler N, Alm B (2008) Sleep in adults with attention deficit hyperactivity disorder (ADHD) before and during treatment with methylphenidate: a controlled polysomnographic study. Sleep 31:375-381. https://doi.org/10.1093/sleep/31.3.375

Steinberg EE, Keiflin R, Boivin JR, Witten IB, Deisseroth K, Janak PH (2013) A causal link between prediction errors, dopamine neurons and learning. Nat Neurosci 16:966-973. https://doi.org/ $10.1038 / \mathrm{nn} .3413$
Strober W (2015) Trypan Blue Exclusion Test of Cell Viability. Curr Protoc Immunol 111:A3 B 1-A3 B 3 doi:https://doi.org/10.1002/ 0471142735.ima03bs111

Swanson JM et al (2007) Etiologic subtypes of attention-deficit/hyperactivity disorder: brain imaging, molecular genetic and environmental factors and the dopamine hypothesis. Neuropsychol Rev 17:39-59. https://doi.org/10.1007/s11065-007-9019-9

Takashima A (1998) Establishment of fibroblast cultures. Curr Protoc Cell Biol Chapter 2: Unit 2.1

Tekin I, Roskoski R Jr, Carkaci-Salli N, Vrana KE (2014) Complex molecular regulation of tyrosine hydroxylase. J Neural Transm (vienna) 121:1451-1481. https://doi.org/10.1007/ s00702-014-1238-7

Thaben PF, Westermark PO (2016) Differential rhythmicity: detecting altered rhythmicity in biological data. Bioinformatics 32:2800 2808. https://doi.org/10.1093/bioinformatics/btw309

Uutela P, Karhu L, Piepponen P, Kaenmaki M, Ketola RA, Kostiainen R (2009) Discovery of dopamine glucuronide in rat and mouse brain microdialysis samples using liquid chromatography tandem mass spectrometry. Anal Chem 81:427-434. https://doi.org/10. $1021 / \mathrm{ac} 801846 \mathrm{w}$

Volkow ND et al (2001) Therapeutic doses of oral methylphenidate significantly increase extracellular dopamine in the human brain. J Neurosci 21:121

Volkow ND, Fowler JS, Wang GJ, Ding YS, Gatley SJ (2002) Role of dopamine in the therapeutic and reinforcing effects of methylphenidate in humans: results from imaging studies. Eur Neuropsychopharmacol 12:557-566. https://doi.org/10.1016/s0924977x(02)00104-9

Volkow ND et al (2007) Depressed dopamine activity in caudate and preliminary evidence of limbic involvement in adults with attention-deficit/hyperactivity disorder. Arch Gen Psychiatry 64:932940. https://doi.org/10.1001/archpsyc.64.8.932

Volkow ND et al (2007) Brain dopamine transporter levels in treatment and drug naive adults with ADHD. Neuroimage 34:1182-1190. https://doi.org/10.1016/j.neuroimage.2006.10.014

Volkow ND et al (2009) Evaluating dopamine reward pathway in ADHD: clinical implications. JAMA 302:1084-1091. https://doi. org/10.1001/jama.2009.1308

Waddell S (2013) Reinforcement signalling in Drosophila; dopamine does it all after all. Curr Opin Neurobiol 23:324-329. https://doi. org/10.1016/j.conb.2013.01.005

Xin J, Fan T, Guo P, Wang J (2019) Identification of functional divergence sites in dopamine receptors of vertebrates. Comput Biol Chem 83:107140. https://doi.org/10.1016/j.compbiolchem.2019. 107140

Yokokura M et al (2020) In vivo imaging of dopamine D1 receptor and activated microglia in attention-deficit/hyperactivity disorder: a positron emission tomography study. Mol Psychiatry. https://doi. org/10.1038/s41380-020-0784-7

Publisher's Note Springer Nature remains neutral with regard to jurisdictional claims in published maps and institutional affiliations. 